\title{
Anoxic conditions are beneficial for abiotic diclofenac removal from water with manganese oxide $\left(\mathrm{MnO}_{2}\right)$
}

\author{
Wenbo Liu ${ }^{1} \cdot$ Nora B. Sutton ${ }^{1} \cdot$ Huub H. M. Rijnaarts ${ }^{1}$ - Alette A. M. Langenhoff ${ }^{1}$
}

Received: 12 July 2017 / Accepted: 14 February 2018 / Published online: 28 February 2018

(C) The Author(s) 2018. This article is an open access publication

\begin{abstract}
This is the first study examining pharmaceutical removal under anoxic conditions with $\mathrm{MnO}_{2}$. This study compares the abiotic removal of seven pharmaceuticals with reactive $\mathrm{MnO}_{2}$ particles in the presence of oxygen (oxic conditions) and in the absence of oxygen (anoxic conditions). Due to the novelty of pharmaceutical removal under anoxic conditions, the influence of phosphate buffer, $\mathrm{pH}$, and $\mathrm{MnO}_{2}$ morphologies is also examined. Results show that over $90 \%$ of diclofenac is removed under anoxic conditions. Additionally, we found that (1) anoxic conditions are beneficial for diclofenac removal with $\mathrm{MnO}_{2}$, (2) phosphate buffer affects the pharmaceutical removal efficiencies, (3) higher pharmaceutical removal is obtained at acidic $\mathrm{pH}$ compared to that at neutral or alkaline conditions, and (4) amorphous $\mathrm{MnO}_{2}$ removes pharmaceuticals better than crystalline $\mathrm{MnO}_{2}$. The pharmaceutical molecular structure and properties, $\mathrm{MnO}_{2}$ properties especially reactive sites of the $\mathrm{MnO}_{2}$ surface, are important for degradation kinetics. This study provides a fundamental basis towards understanding pharmaceutical degradation with $\mathrm{MnO}_{2}$ under anoxic conditions, and development of a cost-effective, sustainable technology for removal of pharmaceuticals from water.
\end{abstract}

Keywords Manganese oxide $\cdot$ Abiotic pharmaceutical removal $\cdot$ Anoxic conditions $\cdot \mathrm{pH}$ effects $\cdot \mathrm{MnO}_{2}$ morphologies $\cdot \mathrm{MnO}_{2}$ reactivity mechanism

\section{Introduction}

Pharmaceuticals in the water cycle threaten the aquatic environment and drinking water resources. Already at low concentrations (ng/L $\sim \mu \mathrm{g} / \mathrm{L})$ (Simazaki et al. 2015; Ternes et al. 2015), pharmaceuticals can be toxic to aquatic organisms (Farré et al. 2008; Gilroy et al. 2014). As a result, pharmaceuticals discharged to water systems are seen as a priority concern of environmental regulators, and the European Union has added one of them, diclofenac, to the "Watchlist" (European Union 2013).

Responsible editor: Vítor Pais Vilar

Electronic supplementary material The online version of this article (https://doi.org/10.1007/s11356-018-1569-2) contains supplementary material, which is available to authorized users.

Alette A. M. Langenhoff alette.langenhoff@wur.nl

1 Sub-department of Environmental Technology, Wageningen University and Research, 6708 WG Wageningen, the Netherlands
Removal of many pharmaceuticals such as carbamazepine, diclofenac, or metoprolol is poor in conventional wastewater treatment processes, such as activated sludge processes, due to the low biodegradability and limited sorption properties of many pharmaceuticals (Vieno and Sillanpaa 2014). Advanced technologies such as ozonation or photodegradation successfully remove selected pharmaceuticals from water and wastewater (He et al. 2016; Javier Benitez et al. 2009). However, these technologies require more energy inputs and operational costs, in addition to often high construction and maintenance costs, and produce intermediate compounds with unknown environmental effects.

A promising alternative method may be based on using manganese oxide $\left(\mathrm{MnO}_{2}\right)$ to remove pharmaceuticals from water. $\mathrm{MnO}_{2}$, mainly referring to the oxide of manganese(IV) in previous studies, is also known as manganese dioxide (Chen et al. 2011; He et al. 2012; Huguet et al. 2013; Huguet et al. 2014). Using $\mathrm{MnO}_{2}$ can efficiently remove persistent pharmaceuticals like carbamazepine, and produce intermediates which are less toxic to the environment (He et al. 2012; Huguet et al. 2013). $\mathrm{MnO}_{2}$ is a common oxidant in soil, sediment, and marine environments, and these environments contain oxic (oxygen present) and/or anoxic 
(oxygen absent) zones (Kuan et al. 2013; Shin and Cheney 2004; $\mathrm{Zhang}$ et al. 2008). Most studies using $\mathrm{MnO}_{2}$ to remove pharmaceuticals are conducted under oxic conditions (Remucal and Ginder-Vogel 2014), because anoxic conditions have no effect or lower removal for pharmaceuticals. Oxygen can accelerate sulfamethazine oxidation by participation in the formation of intermediates (Gao et al. 2012), and for levofloxacin removal, rates under oxic and anoxic conditions are indifferent ( $\mathrm{Li}$ et al. 2015).

Overall, these studies indicate that little is known about the abiotic removal of pharmaceuticals under anoxic conditions with $\mathrm{MnO}_{2}$. Further investigation under anoxic conditions might contribute to understanding how to improve the pharmaceutical removal with $\mathrm{MnO}_{2}$. From an application perspective, water treatment technologies commonly include oxic and anoxic steps. Investigating pharmaceutical removal under anoxic conditions with $\mathrm{MnO}_{2}$ may extend the application of this pharmaceutical removal technology. Additionally, applying anoxic conditions can reduce the construction and operation cost of maintaining oxic conditions in water treatment systems, which is an extra benefit using anoxic conditions. Furthermore, the effect of oxygen on pharmaceutical removal is inconsistent in different studies. Therefore, more studies are required to address pharmaceutical removal with $\mathrm{MnO}_{2}$ under both oxic and anoxic conditions, and to improve the understanding of the removal mechanisms.

Phosphate, $\mathrm{pH}$, and $\mathrm{MnO}_{2}$ morphologies are known to affect the removal of organic compounds with $\mathrm{MnO}_{2}$ (Gao et al. 2012; Shin and Cheney 2004; Yao and Millero 1996). For example, various $\mathrm{MnO}_{2}$ morphologies have been tested to remove pharmaceuticals and other organic compounds, with amorphous $\mathrm{MnO}_{2}$ (birnessite) as most effective and most used (Remucal and Ginder-Vogel 2014). However, little is known about how these parameters affect the removal process under anoxic conditions.

In this study, a series of batch experiments with pharmaceuticals were conducted under oxic and anoxic conditions simulating the conditions encountered in nature as well as in wastewater treatment facilities. Seven widely used pharmaceuticals were selected and tested in the experiments. The effects of oxygen, phosphate, $\mathrm{pH}$, and $\mathrm{MnO}_{2}$ morphologies were studied to better understand the removal processes involved and to optimize these towards the application of technology using reactive $\mathrm{MnO}_{2}$ for pharmaceutical removal.

\section{Materials and methods}

\section{Chemicals}

Caffeine, carbamazepine, diclofenac, metoprolol, naproxen, and propranolol were purchased from Sigma-Aldrich while ibuprofen was purchased from MP Biomedicals (detailed information in Table S1). Other chemicals were purchased from Sigma-Aldrich at $98 \%$ purity (for solids), or at HPLC or UPLC quality (for solvents). Pharmaceutical stocks were prepared with ultrapure water $(18.2 \mathrm{M} \Omega \mathrm{cm}$, TOC $=18 \mathrm{ppb}$, Millipore, USA) and stored in amber glass bottles at $-20^{\circ} \mathrm{C}$. Other solutions were prepared with demineralized water (demiwater). Details are described in Text S1.

\section{$\mathrm{MnO}_{2}$ preparation}

Amorphous $\mathrm{MnO}_{2}$ was obtained by freshly synthesizing prior to experiments as described (Langenhoff et al. 1997). Briefly, equal amounts of $\mathrm{MnCl}_{2}$ and $\mathrm{KMnO}_{4}$ were mixed, $\mathrm{pH}$ level was adjusted to $\sim 10$ with $\mathrm{NaOH}$, and $\mathrm{MnO}_{2}$ was washed by centrifugation (Text S2). Amorphous $\mathrm{MnO}_{2}$ was used in all experiments unless specification. Crystalline $\mathrm{MnO}_{2}$ was purchased from Sigma-Aldrich (Fig. S1, S2).

\section{Batch experiments}

One hundred twenty-five-milliliter glass bottles were filled with $50 \mathrm{~mL} \mathrm{MnO}_{2}$ suspension $(7 \mathrm{mM})$ in demiwater. Oxic experiments were prepared at atmospheric oxygen level. Experiments under anoxic conditions were prepared in the anaerobic glovebox with anoxic water and closed with a rubber stopper and aluminum cap before taking them out of the anaerobic glovebox. Outside the glovebox, the headspace was exchanged with $100 \% \mathrm{~N}_{2}$. All the experimental bottles were closed with rubber stoppers, crimped with aluminum caps, wrapped in aluminum foil to prevent photodegradation, and incubated without shaking at $30^{\circ} \mathrm{C}$.

Experiments were started by spiking bottles to achieve the final pharmaceutical concentration of $1 \mathrm{mg} \mathrm{L}^{-1}$. Aliquots were collected, and reactions were quenched immediately for analysis by centrifugation (10,000 rpm for $10 \mathrm{~min}$ ). Blank experiments without $\mathrm{MnO}_{2}$ were prepared and conducted simultaneously with each batch of experiments. Sample collection and preparation before analysis are described in Text S3.

Experiments in $50 \mathrm{mM}$ phosphate buffer with only diclofenac were conducted to compare the process under oxic and anoxic conditions. In addition, effects of $\mathrm{pH}$ and $\mathrm{MnO}_{2}$ morphologies under anoxic conditions were investigated with phosphate buffer solutions at $\mathrm{pH} 4 \sim 5$ (4.5), $\mathrm{pH} 7.0$, and pH 8 9 (8.5) (Text S1).

\section{Analysis}

The pharmaceutical analysis was conducted as described previously using an ultra-performance liquid chromatography (UPLC, ultimate 3000, Thermo, USA) with a diode array detector (He et al. 2016). The $\mathrm{pH}$ level was determined by a pH meter (PHM210, MeterLab, Radiometer analytical). The $\mathrm{Mn}^{2+}$ analysis was conducted by an inductively coupled 
plasma spectrometer with optical emission spectroscopy (ICPOES). $\mathrm{MnO}_{2}$ morphologies were characterized by X-ray diffraction. The $\mathrm{MnO}_{2}$ before and after the reaction with diclofenac and metoprolol was characterized via a Fouriertransform infra-red (FTIR, Bruker TENSOR 27) spectrometer. The figures of this study are analyzed and generated by Origin Pro 2015 and Microsoft PowerPoint 2007. Details are described in Text S3.

\section{Results and discussion}

\section{Pharmaceutical removal under oxic versus anoxic conditions}

In the absence of $\mathrm{MnO}_{2}$, no removal is observed for all seven pharmaceuticals within $24 \mathrm{~h}$ under both oxic and anoxic conditions in all experiments (Table S3). In the presence of $\mathrm{MnO}_{2}$, metoprolol, propranolol, and diclofenac are removed within $24 \mathrm{~h}$ in both demiwater (Fig. 1a, b) and phosphate buffer (Fig. 1c), while no removal is observed for the other four pharmaceuticals (Fig. S3). Furthermore, the results show that removal efficiency of diclofenac is higher under anoxic conditions, while higher removal is observed under oxic conditions for metoprolol and propranolol. Diclofenac removal efficiencies of $78 \%$ under anoxic conditions and $59 \%$ under oxic conditions were observed after $24 \mathrm{~h}$, incubating a solution of mixed pharmaceuticals in demineralized water (Fig. 1a). However, only $33 \%$ metoprolol was removed under anoxic conditions compared to $69 \%$ under oxic conditions. Similarly, 51\% propranolol was removed under anoxic conditions compared to $84 \%$ under oxic conditions (Fig. 1a). Diclofenac removal efficiency in a mixture together with other six pharmaceuticals (Fig. 1a) was found to be lower than that in a demiwater system which only diclofenac was present (Fig. 1b). Under anoxic conditions, 92\% diclofenac is removed with $\mathrm{MnO}_{2}$, while under oxic conditions, 69\% diclofenac removal is observed (Fig. 1b).

In order to eliminate the effects of $\mathrm{pH}$ and ionic strength on pharmaceutical removal with $\mathrm{MnO}_{2}$ (Gao et al. 2012; Huguet et al. 2013), we control $\mathrm{pH}(\sim 7)$ with $50 \mathrm{mM}$ phosphate buffer and maintain the ionic strength $(0.1 \mathrm{M})$ with $\mathrm{NaCl}$. In further experiments with phosphate buffer, $90 \%$ of diclofenac is removed under anoxic conditions while nearly complete removal of diclofenac is observed under oxic conditions (Fig. 1c). The removal efficiency of diclofenac is similar under anoxic and oxic conditions. In previous studies, removal efficiency of organic matters including pharmaceuticals under anoxic conditions is either similar or lower than that under oxic conditions (Barrett and McBride 2005; Gao et al. 2012; Zhang and Huang 2005a). However, we notably observe that the removal efficiency of diclofenac under anoxic conditions can be higher than that under oxic conditions. This unique result directs our further studies on the mechanism of pharmaceutical removal under anoxic conditions with $\mathrm{MnO}_{2}$.

A pseudo-first-order model with an initial incubation period was applied to analyze the removal kinetics (Table 1), as performed in previous studies under oxic conditions (Jiang et al. 2010a; Zhang et al. 2008; Zhang and Huang 2005a). Comparison of the initial removal rate $\left(r_{\text {obs, init }}\right)$ and the initial removal rate constant $\left(k_{\text {obs, init }}\right)$ of different pharmaceuticals shows that oxygen affects pharmaceutical removal with $\mathrm{MnO}_{2}$. In demiwater with the pharmaceutical mixture and with only diclofenac, diclofenac removal is accelerated under anoxic conditions; metoprolol and propranolol removal rates are lower under anoxic conditions. Furthermore, diclofenac was removed at the highest rate when dissolved as a sole compound in oxic phosphate buffer containing $\mathrm{MnO}_{2}$.

\section{Influence of $\mathrm{pH}$ and $\mathrm{MnO}_{2}$ morphologies on diclofenac removal}

$\mathrm{pH}$ is an important parameter affecting pharmaceutical removal with $\mathrm{MnO}_{2}$. Previous studies show that $\mathrm{MnO}_{2}$ morphologies also influence pharmaceutical removal (Shin and Cheney 2004). However, our novel observation of diclofenac removal under anoxic conditions with $\mathrm{MnO}_{2}$ indicates that the removal mechanisms of pharmaceuticals with $\mathrm{MnO}_{2}$ under anoxic conditions might be different from removal mechanisms under oxic conditions. Therefore, it is important to investigate the effect of $\mathrm{pH}$ and $\mathrm{MnO}_{2}$ morphologies on diclofenac removal to understand the removal mechanism. We investigate the effect of $\mathrm{pH}$ and $\mathrm{MnO}_{2}$ morphologies using both amorphous $\mathrm{MnO}_{2}$ and crystalline $\mathrm{MnO}_{2}$ under anoxic conditions at $\mathrm{pH} \sim 4.5, \mathrm{pH} \sim 7.0$, and $\mathrm{pH} \sim 8.5$ established with a $50 \mathrm{mM}$ phosphate buffer.

Diclofenac removal efficiencies with $\mathrm{MnO}_{2}$ under anoxic conditions are inversely related to $\mathrm{pH}$ (Table 2). Within $48 \mathrm{~h}$, diclofenac removal under anoxic conditions varies from $100 \%$ at around $\mathrm{pH} \sim 4.5$ and $\mathrm{pH} \sim 7.0$, to $70 \%$ at $\mathrm{pH} \sim 8.5$ with amorphous $\mathrm{MnO}_{2}$. In contrast, diclofenac removal is notably lower with crystalline $\mathrm{MnO}_{2}$. Only $21 \%$ of diclofenac is removed with crystalline $\mathrm{MnO}_{2}$ at $\mathrm{pH} \sim 4.5$. In the experiments carried out at $\mathrm{pH} \sim 7.0$ and $\mathrm{pH} \sim 8.5$, no diclofenac removal is observed with crystalline $\mathrm{MnO}_{2}$.

\section{Discussion}

Generally, removal of organic matters with $\mathrm{MnO}_{2}$ is a twostep process including adsorption and oxidation (Remucal and Ginder-Vogel 2014). The contribution of the two steps is various from different compounds (He et al. 2012; Xu et al. 2008; Zhang and Huang 2005b). Under oxic conditions, pharmaceutical removal can be accelerated by oxygen (Gao et al. 2012). However, this fails to explain why anoxic conditions are suitable for diclofenac removal in demiwater when oxygen is not 

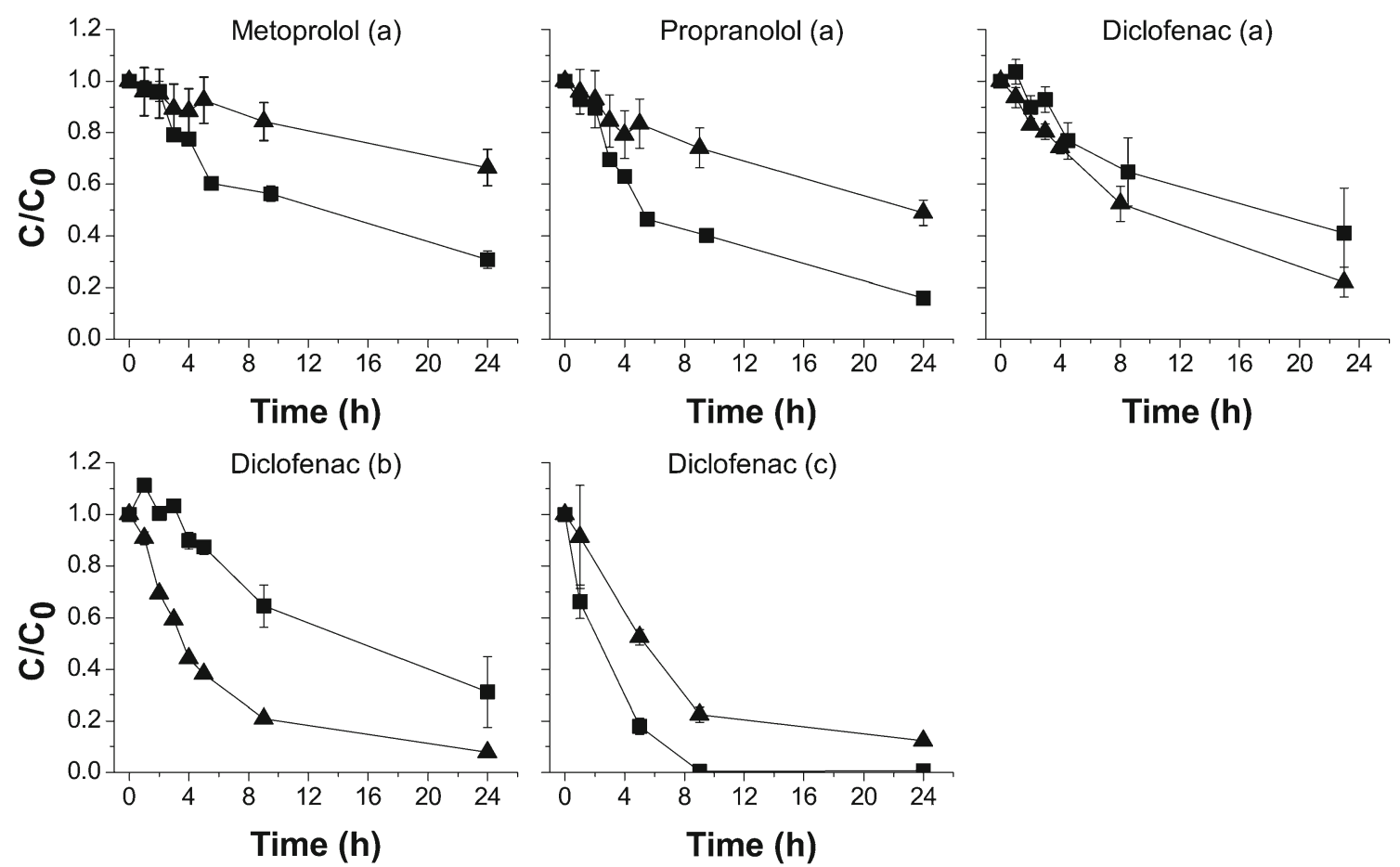

Fig. 1 Pharmaceutical removal with $\mathrm{MnO}_{2}$ in demiwater with pharmaceutical mixture (a), demiwater with only diclofenac solution (b), phosphate buffer with only diclofenac solution under oxic conditions (black square) and anoxic conditions (black up-pointing

present to participate in the removal process (Fig. S4). There are different intermediates formed under oxic and anoxic conditions during diclofenac removal with $\mathrm{MnO}_{2}$ (Fig. S4, S5). These intermediates have different adsorption affinities for the reactive sites on the $\mathrm{MnO}_{2}$ surface, which is possibly the key to explaining the differences between oxic and anoxic conditions. Based on the results, two factors appear to influence the efficiency of pharmaceutical removal and are elaborated below: (1) the pharmaceutical molecular structure and chemical properties, and (2) the $\mathrm{MnO}_{2}$ properties. triangle) (c). Experimental conditions: $\left[\mathrm{MnO}_{2}\right]_{0}=7 \mathrm{mM}$, $[\text { pharmaceutical }]_{0}=1 \mathrm{mg} \mathrm{L}^{-1}, \mathrm{pH} \sim 8.5$. In phosphate buffer with diclofenac solution, [phosphate] $=50 \mathrm{mM}$, [ionic strength] $=0.1 \mathrm{M}$. Error bars are standard deviations determined

\section{Pharmaceutical molecular structure and chemical properties}

The molecular structure and chemical properties of pharmaceuticals are important in organic compound removal with $\mathrm{MnO}_{2}$. Previous studies show that oxidation with $\mathrm{MnO}_{2}$ in the presence of oxygen involves cleavage of the $\mathrm{C}-\mathrm{N}$ bond of the organic compound. Metoprolol and propranolol have $\mathrm{C}-\mathrm{N}$ bonds, in which the $\mathrm{N}$ atom is bound to an alkyl group. These compounds are similar to those tested in previous studies (Table S1, S2) in which oxic conditions promote the

Table 1 Initial removal rate $\left(r_{\text {obs, init }}, \mathrm{mg} \mathrm{L}^{-1} \mathrm{~h}^{-1}, R^{2}=0.80 \sim 0.97\right)$ and initial removal rate constant $\left(k_{\text {obs, init }}, \mathrm{h}^{-1}, R^{2}=0.85 \sim 0.99\right)$ of pharmaceutical removal with $\mathrm{MnO}_{2}$ based on pseudo-first-order in first $5 \mathrm{~h}$

\begin{tabular}{|c|c|c|c|c|c|c|c|}
\hline \multirow[t]{3}{*}{ Experimental solution } & \multirow[t]{3}{*}{ Matrix } & \multirow[t]{3}{*}{$\mathrm{pH}$} & \multirow[t]{3}{*}{ Compound(s) } & \multicolumn{2}{|c|}{$r_{\text {obs, init }}$} & \multicolumn{2}{|c|}{$k_{\text {obs, init }}$} \\
\hline & & & & \multicolumn{2}{|c|}{$\left(10^{-2} \mathrm{mg} \mathrm{L}^{-1} \mathrm{~h}^{-1}\right)$} & \multicolumn{2}{|c|}{$\left(10^{-2} \mathrm{~h}^{-1}\right)$} \\
\hline & & & & Oxic & Anoxic & Oxic & Anoxic \\
\hline \multirow[t]{3}{*}{ Mixture of seven pharmaceutical } & \multirow[t]{3}{*}{ Demiwater } & \multirow[t]{3}{*}{$\sim 8.5$} & Metoprolol & 7.39 & $2.98^{\mathrm{a}}$ & 9.21 & 3.18 \\
\hline & & & Propranolol & 10.10 & 4.02 & 14.18 & 4.48 \\
\hline & & & Diclofenac & 5.33 & 6.48 & 5.96 & 7.49 \\
\hline Only diclofenac present in solution & Demiwater & $\sim 8.5$ & Diclofenac ${ }^{\mathrm{b}}$ & 4.70 & 9.06 & 5.56 & 18.13 \\
\hline Only diclofenac present in solution & $50 \mathrm{mM}$ phosphate buffer & $\sim 7.0$ & Diclofenac ${ }^{\mathrm{b}}$ & 10.48 & 8.73 & 57.32 & 16.60 \\
\hline
\end{tabular}

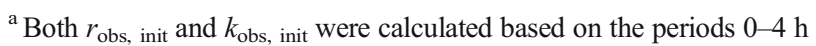

${ }^{\mathrm{b}}$ Both $r_{\mathrm{obs} \text {, init }}$ and $k_{\mathrm{obs}}$, init were calculated based on the periods $0-9 \mathrm{~h}$ 
Table 2 Diclofenac removal efficiency under anoxic conditions at different $\mathrm{pH}$ conditions with two $\mathrm{MnO}_{2}$ morphologies after $48 \mathrm{~h}$. Experimental conditions: $\left[\mathrm{MnO}_{2}\right]_{0}=7 \mathrm{mM},[\text { diclofenac }]_{0}=1 \mathrm{mg} \mathrm{L}{ }^{-1}$, [ionic strength] $=0.1 \mathrm{M}$

\begin{tabular}{llll}
$\mathrm{MnO}_{2}$ morphologies & $\sim \mathrm{pH} 4.5(\%)$ & $\sim \mathrm{pH} \mathrm{7.0( \% )}$ & $\sim \mathrm{pH} 8.5(\%)$ \\
\hline Amorphous $\mathrm{MnO}_{2}$ & 100 & 100 & 71 \\
Crystalline $\mathrm{MnO}_{2}$ & 21 & 0 & 0
\end{tabular}

removal. This $\mathrm{C}-\mathrm{N}$ bond cleavage can result in the formation of radicals in the presence of oxygen (Barrett and McBride 2005; Gao et al. 2012). Oxidation of diclofenac involves hydroxylation and decarboxylation instead of $\mathrm{C}-\mathrm{N}$ cleavage (Huguet et al. 2013), which is a different mechanism than that of metoprolol and propranolol. This shows that the removal mechanism is closely related to the pharmaceutical molecular structure and chemical properties.

The pharmaceutical's properties are also affected by $\mathrm{pH}$. Due to the low $\mathrm{pKa}$ of diclofenac $(\mathrm{pKa}=4.15)$, lower $\mathrm{pH}$ level results in a less negatively charged compound. This leads to less electrostatic repulsion between diclofenac and $\mathrm{MnO}_{2}$, which is also negatively charged (Murray 1974). It is speculated that lower $\mathrm{pH}$ level will lead to a higher affinity of diclofenac to adsorb onto the $\mathrm{MnO}_{2}$ surface and therefore has a more favorable first step in removal with $\mathrm{MnO}_{2}$.

\section{$\mathrm{MnO}_{2}$ properties}

The properties of $\mathrm{MnO}_{2}$ are also affected by $\mathrm{pH}$. At acidic $\mathrm{pH}$, $\mathrm{MnO}_{2}$ is also less negatively charged due to its isoelectric point, resulting in less electrostatic repulsion and better adsorption of organic compounds. In addition, the $\mathrm{MnO}_{2}$ redox potential increases from $0.76 \mathrm{~V}$ at $\mathrm{pH} 8.0$ to $0.99 \mathrm{~V}$ at $\mathrm{pH} 4.0$ (Lin et al. 2009). Thus, the degradation reaction is energetically more favorable at lower $\mathrm{pH}$. Both factors may lead to faster degradation, as shown in our study (Table 2). This experiment uses neutral $\mathrm{pH}$, which was found unfavorable for oxidation of pharmaceuticals in previous studies (Chen et al. 2011; He et al. 2012; Xu et al. 2008). In addition, there are less protons at the low redox potential of $\mathrm{MnO}_{2}$ at higher $\mathrm{pH}$, which is crucial for the electron transfer from $\mathrm{Mn}(\mathrm{IV})$ to $\mathrm{Mn}(\mathrm{II})$. As a result, no removal of caffeine, carbamazepine, ibuprofen, and naproxen was observed in this study (Fig. S3), while the removal efficiency of metoprolol and propranolol is low under both oxic and anoxic conditions.

Different $\mathrm{MnO}_{2}$ morphologies have different properties affecting diclofenac removal. In our research, diclofenac removal is better with amorphous $\mathrm{MnO}_{2}$ than that with crystalline $\mathrm{MnO}_{2}$, which is in line with previously reported findings (Remucal and Ginder-Vogel 2014; Shin and Cheney 2004; Ukrainczyk and Mcbride 1992). Amorphous $\mathrm{MnO}_{2}$ particles are usually smaller than crystalline particles. Thus, the amorphous $\mathrm{MnO}_{2}$ particles have a larger surface area, which increases pharmaceutical removal. Unfortunately, due to the analytical limits, size analysis of amorphous $\mathrm{MnO}_{2}$ appeared technically not feasible (Fig. S6). In addition, amorphous $\mathrm{MnO}_{2}$ contains small amounts of $\mathrm{Mn}$ (III) which can increase $\mathrm{MnO}_{2}$ reactivity and oxidizing ability (Remucal and Ginder-Vogel 2014), thus promoting pharmaceutical removal even further.

In the presence of phosphate, diclofenac removal with $\mathrm{MnO}_{2}$ is slightly enhanced under oxic conditions than that under anoxic conditions. Using $\mathrm{O}_{2}$ to oxidize $\mathrm{Mn}$ (II) to $\mathrm{Mn}$ (III) is a thermodynamically favorable reaction. In the presence of phosphate buffer, phosphate can form $\mathrm{Mn}_{3}\left(\mathrm{PO}_{4}\right)_{2}$ with $\mathrm{Mn}$ (II) from diclofenac oxidation (Eq. 1) (Jin et al. 2014).

$3 \mathrm{Mn}^{2+}+2 \mathrm{PO}_{4}^{3-} \rightarrow \mathrm{Mn}_{3}\left(\mathrm{PO}_{4}\right)_{2}$

Computations show that the chemical structure of $\mathrm{Mn}_{3}\left(\mathrm{PO}_{4}\right)_{2}$ can stabilize $\mathrm{Mn}(\mathrm{III})$ and thereby facilitate $\mathrm{Mn}$ (II) oxidation to $\mathrm{Mn}(\mathrm{III})$ under oxic conditions (Jin et al. 2014). The $\mathrm{Mn}^{2+}$ analysis shows the presence of higher $\mathrm{Mn}$ (II) concentrations in phosphate buffer than in demiwater, which we explain as a result of larger amounts of $\mathrm{Mn}(\mathrm{III})$ formed under oxic conditions. Higher Mn(III) concentration is likely the reason that more diclofenac is removed than under anoxic conditions, as we observed (Fig. 1) and mechanistically present in Fig. 2.

\section{Reactive sites on the $\mathrm{MnO}_{2}$ surface}

The adsorption of organic molecules onto a reactive metal oxide surface is found to be the key parameter dictating removal of many organic compounds, and specifically to reactive sites on the $\mathrm{MnO}_{2}$ surface (He et al. 2012; Xu et al. 2008; Zhang and Huang 2005b). Our results with the mixed pharmaceutical solution in the demiwater suggest competition for reactive sites between diclofenac and the other different pharmaceuticals. This is evidenced by the lower diclofenac remov$\mathrm{al}$ in the presence of other pharmaceuticals (Fig. 1a, b).

Based on our FTIR results, there was no obvious disappearance of reactive sites during diclofenac removal with $\mathrm{MnO}_{2}$ under both oxic and anoxic conditions (Fig. S5), possibly due to a relatively high concentration of $\mathrm{MnO}_{2}$ in the experiment. However, it is clear that the FTIR spectrums are different between the $\mathrm{MnO}_{2}$ before and after reacting with diclofenac, especially under anoxic conditions. This indicates that the intermediates from diclofenac change the $\mathrm{MnO}_{2}$ structure. This change may contribute to the better diclofenac removal with $\mathrm{MnO}_{2}$ under anoxic conditions.

In phosphate buffer, phosphate can reduce the diclofenac removal by being adsorbed onto the $\mathrm{MnO}_{2}$ surface and competing with DFC for the reactive sites of $\mathrm{MnO}_{2}$ (Yao and Millero 1996). Consequently, although the lower $\mathrm{pH}$ level in phosphate buffer should promote diclofenac removal $(\mathrm{pH} 7$ in 
(a) In demiwater

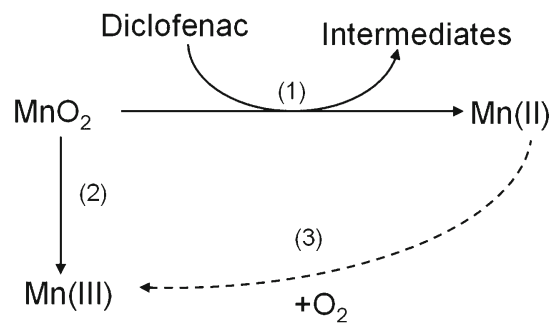

(b) In phosphate buffer

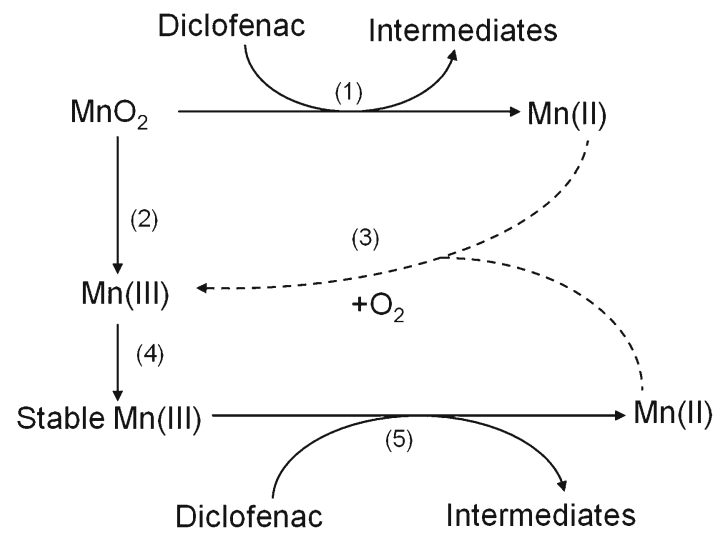

Fig. 2 The effects of phosphate on diclofenac removal with $\mathrm{MnO}_{2}$ under oxic and anoxic conditions. Solid lines are processes under both oxic and anoxic conditions; dashed lines are the processes only under oxic conditions. (1) $\mathrm{MnO}_{2}$ removes diclofenac via oxidation and produces Mn(II) (Forrez et al. 2010; Huguet et al. 2013); (2) Mn(III) comes from $\mathrm{MnO}_{2}$ synthesis process (Remucal and Ginder-Vogel 2014); (3) $\mathrm{Mn}$ (II) is oxidized to $\mathrm{Mn}$ (III) by $\mathrm{O}_{2}$; (4) $\mathrm{Mn}$ (III) from $\mathrm{MnO}_{2}$ was stabilized by $\mathrm{Mn}_{3}\left(\mathrm{PO}_{4}\right)_{2}$ formed via Eq. 1 (Jin et al. 2014); (5) Mn(III) oxidizes diclofenac and produces $\mathrm{Mn}(\mathrm{II})$

buffer versus $\mathrm{pH} 8 \sim 9$ in demiwater), diclofenac removal is better in demiwater because $\mathrm{MnO}_{2}$ reactive sites are not blocked by phosphate (Table 1). However, similar removal efficiencies and kinetics in demiwater and phosphate buffer under anoxic conditions are observed (Fig. 1). This indicates there is a mechanism promoting diclofenac removal in phosphate buffer, which competes with the inhibition by phosphate adsorbing and occupying the reactive sites on the $\mathrm{MnO}_{2}$ surface. From previous studies, it is known that $\mathrm{Mn}$ (II) can occupy reactive sites on the $\mathrm{MnO}_{2}$ surface and then inhibit pharmaceutical removal (He et al. 2012; Xu et al. 2008). Our removal results in phosphate buffer show that $1.54 \mu \mathrm{M}$ $\mathrm{Mn}^{2+}$ was generated under oxic conditions while $2.16 \mu \mathrm{M}$ was generated under anoxic conditions. Less Mn(II) under oxic conditions resulted in possibly less formation of $\mathrm{Mn}_{3}\left(\mathrm{PO}_{4}\right)_{2}$ via Eq. 1, which presumably led to more available reactive sites for diclofenac removal. Under anoxic conditions, the balance of these promoting and inhibiting effects by adsorbing phosphate leads to similar diclofenac removal in demiwater and phosphate buffer.

\section{Conclusions}

In conclusion, this study addresses the knowledge gap surrounding pharmaceutical removal under anoxic conditions (absence of oxygen) with $\mathrm{MnO}_{2}$. Results show that anoxic conditions are beneficial for diclofenac removal with $\mathrm{MnO}_{2}$. In demiwater, anoxic conditions show higher diclofenac removal compared to oxic conditions. In phosphate buffer, anoxic conditions resulted in similar diclofenac removal $(10 \%$ difference) comparing to oxic conditions. Both $\mathrm{pH}$ and $\mathrm{MnO}_{2}$ morphologies influence the removal process and its efficiency. Since both demiwater and phosphate buffer suggest that anoxic conditions are as good as, or even better than, oxic conditions in diclofenac removal from water with $\mathrm{MnO}_{2}$, the less potential cost in processes under anoxic conditions is more attractive and promising in treating water and wastewater containing pharmaceuticals. The results show that amorphous $\mathrm{MnO}_{2}$ is the most suitable material for further research and application, and the most optimal and applicable conditions are at neutral $\mathrm{pH}$ in anoxic systems. By using a more favorable $\mathrm{pH}$ (acidic $\mathrm{pH}$ ), the removal of all the pharmaceuticals can be expected under anoxic conditions. To our knowledge, this is the first study discussing pharmaceutical removal with $\mathrm{MnO}_{2}$ under anoxic conditions. Using anoxic conditions is less energy-consuming compared to using oxic conditions (aeration), and $\mathrm{Mn}$ can be regenerated and recycled via a biological or chemical process (Jiang et al. 2010b; Liu et al., Biological regeneration of manganese (IV) and iron (III) for anaerobic metal oxide-mediated removal of pharmaceuticals from water, submitted; Tebo et al. 2004). Overall, this study contributes to (1) understanding pharmaceutical removal in the absence of oxygen, (2) improving the knowledge of pharmaceutical removal mechanisms with $\mathrm{MnO}_{2}$, and (3) providing fundamental insight into a $\mathrm{MnO}_{2}$-based process which may lead to a more sustainable technology for pharmaceutical removal.

Acknowledgements The authors appreciate the support from Hans Beijleveld, Jan Kubiak, Ilse Gerrits, and Jean Slangen and their help with the chemical analyses. Special thanks go to Sidiharam Pujari for the FTIR analysis and Harry Baptist for the freeze-drying procedure.

Funding information The work was supported by the China Scholarship Council (File No. 201308610161) and Wageningen University and Research.

\section{Compliance with ethical standards}

Conflict of interest The authors declare that they have no conflict of interest.

Open Access This article is distributed under the terms of the Creative Commons Attribution 4.0 International License (http:// creativecommons.org/licenses/by/4.0/), which permits unrestricted use, distribution, and reproduction in any medium, provided you give appropriate credit to the original author(s) and the source, provide a link to the Creative Commons license, and indicate if changes were made. 


\section{References}

Barrett KA, McBride MB (2005) Oxidative degradation of glyphosate and aminomethylphosphonate by manganese oxide. Environ Sci Technol 39:9223-9228. https://doi.org/10.1021/es051342d

Chen G, Zhao L, Dong Y-h (2011) Oxidative degradation kinetics and products of chlortetracycline by manganese dioxide. J Hazard Mater 193:128-138. https://doi.org/10.1016/j.jhazmat.2011.07.039

European Union (2013) Directive 2013/39/EU of the European Parliament and of the Council. Off J Eur Union. http://eur-lex. europa.eu/legal-content/EN/TXT/PDF/?uri=CELEX: 32013L0039\&from=EN. Accessed 6 Mar 2017

Farré M, Pérez S, Kantiani L, Barceló D (2008) Fate and toxicity of emerging pollutants, their metabolites and transformation products in the aquatic environment. TrAC-Trends Anal Chem 27:991-1007. https://doi.org/10.1016/j.trac.2008.09.010

Forrez I, Carballa M, Verbeken K, Vanhaecke L, Ternes T, Boon N, Verstraete W (2010) Diclofenac oxidation by biogenic manganese oxides. Environ Sci Technol 44:3449-3454. https://doi.org/10. 1021/es9027327

Gao J, Hedman C, Liu C, Guo T, Pedersen JA (2012) Transformation of sulfamethazine by manganese oxide in aqueous solution. Environ Sci Technol 46:2642-2651. https://doi.org/10.1021/es202492h

Gilroy ÈAM, Klinck JS, Campbell SD, McInnis R, Gillis PL, de Solla SR (2014) Toxicity and bioconcentration of the pharmaceuticals moxifloxacin, rosuvastatin, and drospirenone to the unionid mussel Lampsilis siliquoidea. Sci Total Environ 487:537-544. https://doi. org/10.1016/j.scitotenv.2014.03.051

He Y, Xu J, Zhang Y, Guo C, Li L, Wang Y (2012) Oxidative transformation of carbamazepine by manganese oxides. Environ Sci Pollut Res 19:4206-4213. https://doi.org/10.1007/s11356-012-0949-2

He Y, Sutton NB, Rijnaarts HHH, Langenhoff AAM (2016) Degradation of pharmaceuticals in wastewater using immobilized $\mathrm{TiO}_{2}$ photocatalysis under simulated solar irradiation. Appl Catal BEnviron 182:132-141. https://doi.org/10.1016/j.apcatb.2015.09.015

Huguet M, Deborde M, Papot S, Gallard H (2013) Oxidative decarboxylation of diclofenac by manganese oxide bed filter. Water Res 47 : 5400-5408. https://doi.org/10.1016/j.watres.2013.06.016

Huguet M, Simon V, Gallard H (2014) Transformation of paracetamol into 1,4-benzoquinone by a manganese oxide bed filter. J Hazard Mater 271:245-251. https://doi.org/10.1016/j.jhazmat.2014.02.017

Javier Benitez F, Acero JL, Real FJ, Roldán G (2009) Ozonation of pharmaceutical compounds: rate constants and elimination in various water matrices. Chemosphere 77:53-59. https://doi.org/10. 1016/j.chemosphere.2009.05.035

Jiang LY, Chen JM, Zhu RY, Huang C, Ji H (2010a) Degradation kinetics and estrogenic activity of $17 \beta$-estradiol removal by aqueous manganese dioxide. J Environ Sci Health A 45:938-945. https://doi.org/ 10.1080/10934521003772329

Jiang S, Kim D-G, Kim J, Ko S-O (2010b) Characterization of the biogenic manganese oxides produced by Pseudomonas putida strain MnB1. Environ Eng Res 15:183-190. https://doi.org/10.4491/eer. 2010.15.4.183

Jin K, Park J, Lee J, Yang KD, Pradhan GK, Sim U, Jeong D, Jang HL, Park S, Kim D, Sung N-E, Kim SH, Han S, Nam KT (2014) Hydrated manganese(II) phosphate $\left(\mathrm{Mn}_{3}\left(\mathrm{PO}_{4}\right)_{2} \cdot 3 \mathrm{H}_{2} \mathrm{O}\right)$ as a water oxidation catalyst. J Am Chem Soc 136:7435-7443. https://doi. org/10.1021/ja5026529

Kuan WH, Hu CY, Liu BS, Tzou YM (2013) Degradation of antibiotic amoxicillin using $1 \times 1$ molecular sieve-structured manganese oxide.
Environ Technol 34:2443-2451. https://doi.org/10.1080/09593330. 2013.772658

Langenhoff AAM, Brouwers-Ceiler DL, Engelberting JHL, Quist JJ, Wolkenfelt JGPN, Zehnder AJB, Schraa G (1997) Microbial reduction of manganese coupled to toluene oxidation. FEMS Microbiol Ecol 22:119-127. https://doi.org/10.1016/S0168-6496(96)00082-7

Li Y, Wei D, Du Y (2015) Oxidative transformation of levofloxacin by $\delta$ $\mathrm{MnO}_{2}$ : products, pathways and toxicity assessment. Chemosphere 119:282-288. https://doi.org/10.1016/j.chemosphere.2014.06.064

Lin K, Liu W, Gant J (2009) Oxidative removal of bisphenol A by manganese dioxide: efficacy, products, and pathways. Environ Sci Technol 43:3860-3864. https://doi.org/10.1021/es900235f

Murray JW (1974) The surface chemistry of hydrous manganese dioxide. J Colloid and Interface Sci 46:357-371. https://doi.org/10.1016/ 0021-9797(74)90045-9

Remucal CK, Ginder-Vogel M (2014) A critical review of the reactivity of manganese oxides with organic contaminants. Environ Sci Processes Impacts 16:1247-1266. https://doi.org/10.1039/ C3EM00703K

Shin JY, Cheney MA (2004) Abiotic transformation of atrazine in aqueous suspension of four synthetic manganese oxides. Colloids Surf A Physicochem Eng Asp 242:85-92. https://doi.org/10.1016/j. colsurfa.2004.04.061

Simazaki D, Kubota R, Suzuki T, Akiba M, Nishimura T, Kunikane S (2015) Occurrence of selected pharmaceuticals at drinking water purification plants in Japan and implications for human health. Water Res 76:187-200. https://doi.org/10.1016/j.watres.2015.02. 059

Tebo BM, Bargar JR, Clement BG, Dick GJ, Murray KJ, Parker D, Verity R, Webb SM (2004) Biogenic manganese oxides: properties and mechanisms of formation. Annu Rev Earth Planet Sci 32:287-328. https://doi.org/10.1146/annurev.earth.32.101802.120213

Ternes T, Joss A, Oehlmann J (2015) Occurrence, fate, removal and assessment of emerging contaminants in water in the water cycle (from wastewater to drinking water). Water Res 72:1-2. https://doi. org/10.1016/j.watres.2015.02.055

Ukrainczyk L, Mcbride MB (1992) Oxidation of phenol in acidic aqueous suspensions of manganese oxides. Clay Clay Miner 40:157166. https://doi.org/10.1346/Ccmn.1992.0400204

Vieno N, Sillanpaa M (2014) Fate of diclofenac in municipal wastewater treatment plant—a review. Environ Int 69:28-39. https://doi.org/10. 1016/j.envint.2014.03.021

Xu L, Xu C, Zhao M, Qiu Y, Sheng GD (2008) Oxidative removal of aqueous steroid estrogens by manganese oxides. Water Res 42: 5038-5044. https://doi.org/10.1016/j.watres.2008.09.016

Yao W, Millero FJ (1996) Adsorption of phosphate on manganese dioxide in seawater. Environ Sci Technol 30:536-541. https://doi.org/10. $1021 / \mathrm{es} 950290 \mathrm{x}$

Zhang H, Huang CH (2005a) Oxidative transformation of fluoroquinolone antibacterial agents and structurally related amines by manganese oxide. Environ Sci Technol 39:4474-4483. https://doi.org/10. $1021 / \mathrm{es} 048166 \mathrm{~d}$

Zhang H, Huang CH (2005b) Reactivity and transformation of antibacterial $\mathrm{N}$-oxides in the presence of manganese oxide. Environ Sci Technol 39:593-601. https://doi.org/10.1021/es048753z

Zhang H, Chen WR, Huang CH (2008) Kinetic modeling of oxidation of antibacterial agents by manganese oxide. Environ Sci Technol 42: 5548-5554. https://doi.org/10.1021/es703143g 